\title{
The crustal dynamics data information system: A resource to support scientific analysis using space geodesy
}

\author{
Carey E. Noll * \\ NASA Goddard Space Fight Center, Code 690. Greenbelt, MD 20771, United States
}

Received 31 Augusi 2009; received in revised form 12 January 2010; accepted 13 January 2010

\begin{abstract}
Since 1982, the Crustal Dynamics Data Information System (CDDIS) has supported the archive and distribution of geodetic data products acquired by the National Aeronautics and Space Administration (NASA) as well as national and international programs. The CDDIS provides easy, timely, and reliable access to a variety of data sets, products, and information about these data. These measurements, obtained from a global network of nearly 650 instruments at more than 400 distinct sites, include DORIS (Doppler Orbitography and Radiopositioning Integrated by Satellite), GNSS (Global Navigation Satellite System), SLR and LLR (Satellite and Lunar Laser Ranging), and VLBI (Very Long Baseline Interferometry). The CDDIS data system and its archive have become increasingly important to many national and international science communities, particularly several of the operational services within the International Association of Geodesy (IAG) and its observing system the Global Geodetic Observing System (GGOS), including the International DORIS Service (IDS), the International GNSS Service (IGS), the International Laser Ranging Service (ILRS), the International VLBI Service for Geodesy and Astrometry (IVS), and the International Earth rotation and Reference frame Service (IERS). Investigations resulting from the data and products available through the CDDIS support research in many aspects of Earth system science and global change. Each month, the CDDIS archives more than one million data and derived product files totaling over 90 Gbytes in volume. In turn, the global user community downloads nearly 1.2 Tbytes (over 10.5 million files) of data and products from the CDDIS each month. The requirements of analysts have evolved since the start of the CDDIS; the specialized nature of the system accommodates the enhancements required to support diverse data sets and user needs. This paper discusses the CDDIS, inchuding background information about the system and its user communities, archive contents, available metadata, and future plans.

Published by Elsevier Ltd. on behalf of COSPAR.
\end{abstract}

Keywords: GNSS; Laser ranging; VLBI; DORIS; Space geodesy; GGOS

\section{Introduction}

Space geodesy is the use of precise measurements between ground-based instruments and objects in space (e.g., orbiting satellites, quasars) to determine positions of points on the Earth, the motion of the Earth's pole and its rotation parameters, the Earth's gravity field and the derivation of its geoid, and monitor variations in these measurements over time. Space geodesy not only enables research in the physics of the solid Earth but also oceano-

\footnotetext{
*Tel.: $+13016146542 ;$ fax: +13016146015

E-matl addres: Carey Nonfratas agew.
}

graphic, atmospheric, and environmental science studies and their impact in global climate research (Plag and Pearlman, 2009). The main techniques used in space geodesy are:

- Global Navigation Satellite System (GNSS), including the U.S. Global Positioning System (GPS), the Russian GLObal NAvigation Satellite System (GLONASS), and, in the future, the European system Galleo.

- Satellite Laser Ranging (SLR) and Lunar Laser Ranging (LLR).

- Very Long Baseline Interferometry (VLBI).

- Doppler Orbitography and Radiopositioning Integrated by Satelite (DORIS). 
Table 1

Overview of space geodetic techniques.

\begin{tabular}{|c|c|c|c|}
\hline Technique & Target & Receiver/transmitter & Measurement \\
\hline DORIS & Satellites equipped with DORIS receiver and uplink hardware & $\begin{array}{l}\text { Beacon transmitting } \\
\text { radiofrequency signals }\end{array}$ & $\begin{array}{l}\text { Doppler shift on tadiofrequency signals } \\
\text { and phase (new receiver version only) }\end{array}$ \\
\hline GNSS & $\begin{array}{l}\text { Satellites (GPS, GLONASS, Gatileo) equipped with precise clocks } \\
\text { transmitting satelite messages such as ephemeris, clock offets, etc. }\end{array}$ & $\begin{array}{l}\text { Dual frequency GNSS } \\
\text { receiver and antenna }\end{array}$ & $\begin{array}{l}\text { Station to satellite pseudorange, phase } \\
\text { delay }\end{array}$ \\
\hline Laser ranging & Satellites equipped with corner cubes/retroreflectors & $\begin{array}{l}\text { Ground-based short- } \\
\text { pulse laser transmitter }\end{array}$ & $\begin{array}{l}\text { Round-trip palst time of -flight from } \\
\text { taser station to satellite }\end{array}$ \\
\hline VLBI & Quasars (microwave frequencies) & $\begin{array}{l}\text { Radio telescope } \\
\text { equipped with } X \text {-and } S \text { - } \\
\text { wideband receivers }\end{array}$ & $\begin{array}{l}\text { Difrerence in signal arrival times } \\
\text { between two observing antennas }\end{array}$ \\
\hline
\end{tabular}

Table 1 above describes each of these techniques and their observation methodologies: targets, instrument, and resulting measurement. Pictures of representative observing instruments are shown in Fig. 1.

Each technique has particular strengths (sce Table 2) in their contributions to scientific investigations; further- more, these different measurement systems provide independent determinations of similar measurements. The table summarizes both the primary and supporting contributors to these study areas that are currently feasible today; it is not meant to include theoretical or possible future roles.
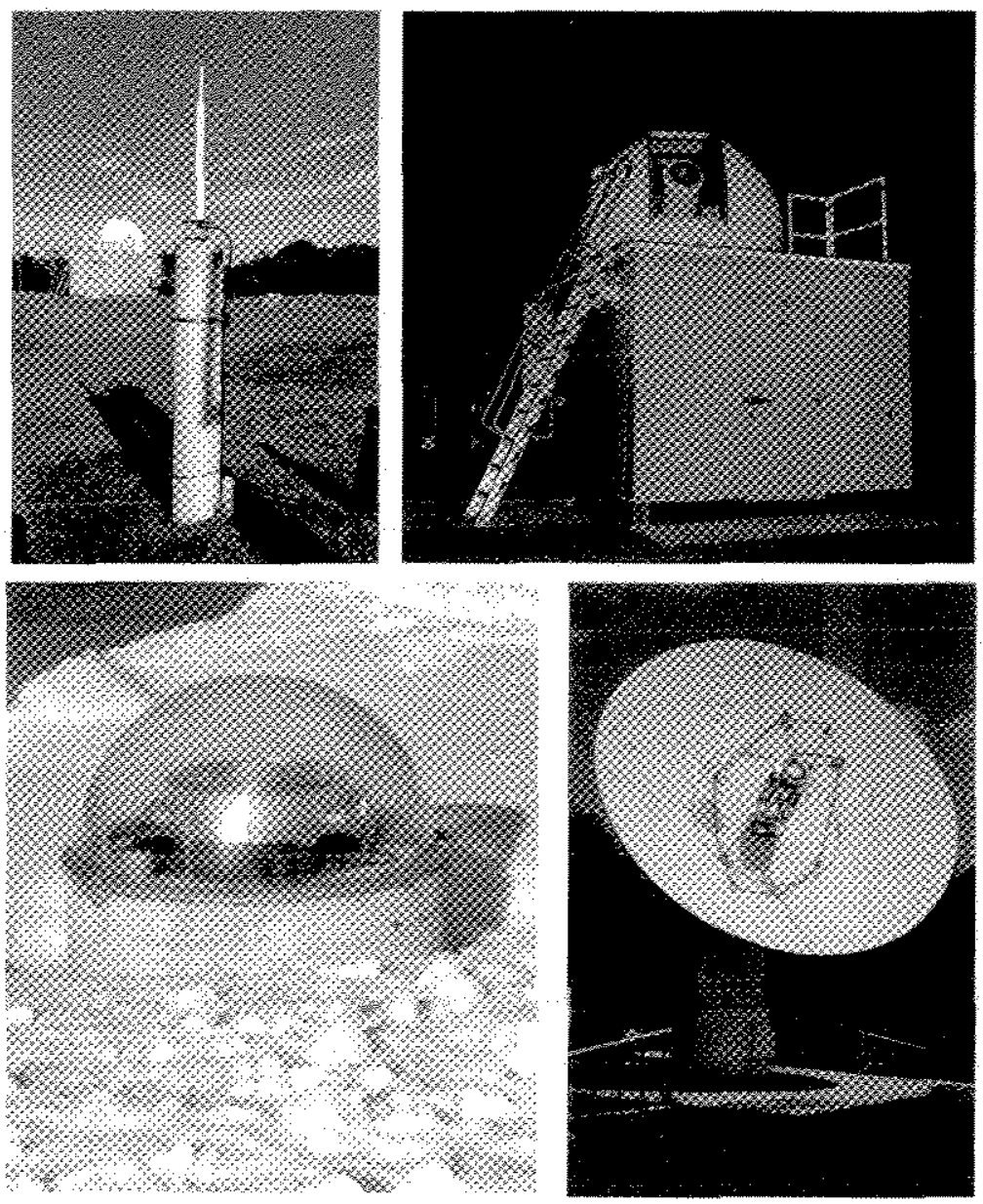

Fig. 1. DORIS beacon (station GREB) mounted on concrete pillar at NASA's Goddard Space Flight Center in Greenbelt MD: USA (top left). Nex? Generation SLR (NGSLR) station perforning nighttme ranging at Greenbelt (top tight). GNSS antema (station GODE) with dome mounted on a concrete pillar at Greenbelt (botiom teft). VL BI antenna (5-m) at Greenbelt (bottom right). Greenbelt is considered a "fundamental station" because of its tanique position as a co-location site for instruments from each of the four space geodesy techniques. (Photos courtesy of NASA). 
Table 2

Scientific contributions of DORIS, GNSS, SLR, and VLBI.

\begin{tabular}{|c|c|c|c|c|}
\hline \multirow[t]{2}{*}{ Scientific contribution } & \multicolumn{4}{|c|}{ Technique } \\
\hline & DORIS & GNSS & SLR & VLBI \\
\hline \multicolumn{5}{|l|}{ Terrestrial reference frome (TRF) } \\
\hline TRF scale and temporal variations & $x$ & $\mathrm{x}$ & $\mathrm{X}$ & $\mathrm{X}$ \\
\hline Network dissemination/access & & $\mathrm{X}$ & & \\
\hline Homogenous network distribution & $\mathrm{X}$ & $X$ & & \\
\hline Celestial reference frame & & & & $\mathrm{X}$ \\
\hline \multicolumn{5}{|l|}{ Precise orbit determination ( $P O D$ ) } \\
\hline Accurate satellite ephemerides & $\mathrm{X}$ & $X$ & $\mathrm{X}$ & \\
\hline Catibration/validation for remote sensing missions, instruments & & $\mathrm{X}$ & $\mathrm{X}$ & \\
\hline Sea level monitoring & $\mathrm{X}$ & $X$ & $\mathrm{X}$ & \\
\hline \multicolumn{5}{|l|}{ Earth orientation parameters ( $E O P$ ) } \\
\hline Polar motion and rates & $x$ & $\mathrm{X}$ & $x$ & $\mathrm{x}$ \\
\hline Length $\cdots$ of $-\mathrm{day}$ & $x$ & $\mathrm{X}$ & $\mathrm{x}$ & $\mathrm{X}$ \\
\hline \multicolumn{5}{|l|}{ Atmosphere } \\
\hline Tropospheric zenith delays & $\mathrm{x}$ & $\mathrm{X}$ & & $\mathrm{x}$ \\
\hline Global maps of ionosphere mean electron content & $\mathrm{x}$ & $\mathrm{X}$ & & \\
\hline Limb sounding for global profiles of water vapor & & $\mathrm{X}$ & & \\
\hline \multicolumn{5}{|l|}{ Gravity } \\
\hline Static and time-varying coefficients of the Earth"s gravity field & $\mathrm{x}$ & $\mathrm{x}$ & $\mathrm{X}$ & \\
\hline Total Earth mass & $\mathrm{x}$ & 8 & $\mathrm{X}$ & \\
\hline Temporal variations of network origin with respect to Earth center of mass & $\mathrm{x}$ & $\mathrm{x}$ & $\mathrm{X}$ & \\
\hline \multicolumn{5}{|l|}{ Timing: } \\
\hline Station and satelite clock solutions & & $\mathrm{X}$ & $x$ & \\
\hline Time and frequency transfer between time laboratories & & $X$ & $x$ & \\
\hline \multicolumn{5}{|l|}{ Fundamental physics } \\
\hline General relativity and alternative theories & & & $x^{*}$ & $x$ \\
\hline Light bending, time dilation & & & & $\mathrm{X}$ \\
\hline
\end{tabular}

Notes. $X$, primary contribution.

$\mathrm{x}$, supporting contribution.

"Contribution from both SLR and LLR.

A key application of space geodesy is the precise determination of positions and velocities of global stations (Fig. 2). These solutions are then used to maintain an International Terrestrial Reference Frame (ITRF), the set of points that realize an ideal reference system. This ITRF provides the stable coordinate system that allows satellite and ground-based measurements to be linked over space and time (Committee on Earth Science and Applications from Space, 2007). The ITRF is a founda tion by which scientists verify that observed temporal changes are geophysical signals rather than artifacts of the measurement system. The ITRF provides for remote monitoring of key contributors to global change, e.g., sea level, sea surface and ice surface topography, crustal deformation, temporal gravity variations, etc. This reference frame also provides the spatial and temporal link between missions.

The Crustal Dynamics Data Information System (CDDIS), htip//catis.nasa.gov, is NASA's data archive and information service supporting the international space geodesy community. For over 25 years, the CDDIS has provided continuous, long-term, public access to geodetic data (mainly GNSS, laser ranging, VLBI, and DORIS) and products derived from these data that are required for a variety of scientific investigations. This research includes the determination of a global TRF and geodetic studies in plate tectonics, earthquake displacements, volcano monitoring, Earth orientation, and atmospheric angular momentum, among others. The specialized nature of the CDDIS permits relatively simple augmentation in order to accommodate diverse data sets and user requirements. The CDDIS serves as one of the primary data centers and core components for the geometric services established under the International Association of Geodesy (IAG), an organization that promotes scientific cooperation and research in geodesy on a global scale.

\section{Background}

Development of the CDDIS began at NASA's Goddard Space Flight Center (GSFC) in 1981 in support of a data management infrastructure for the NASA program, the Crustal Dynamics Project (CDP). Following the successful 


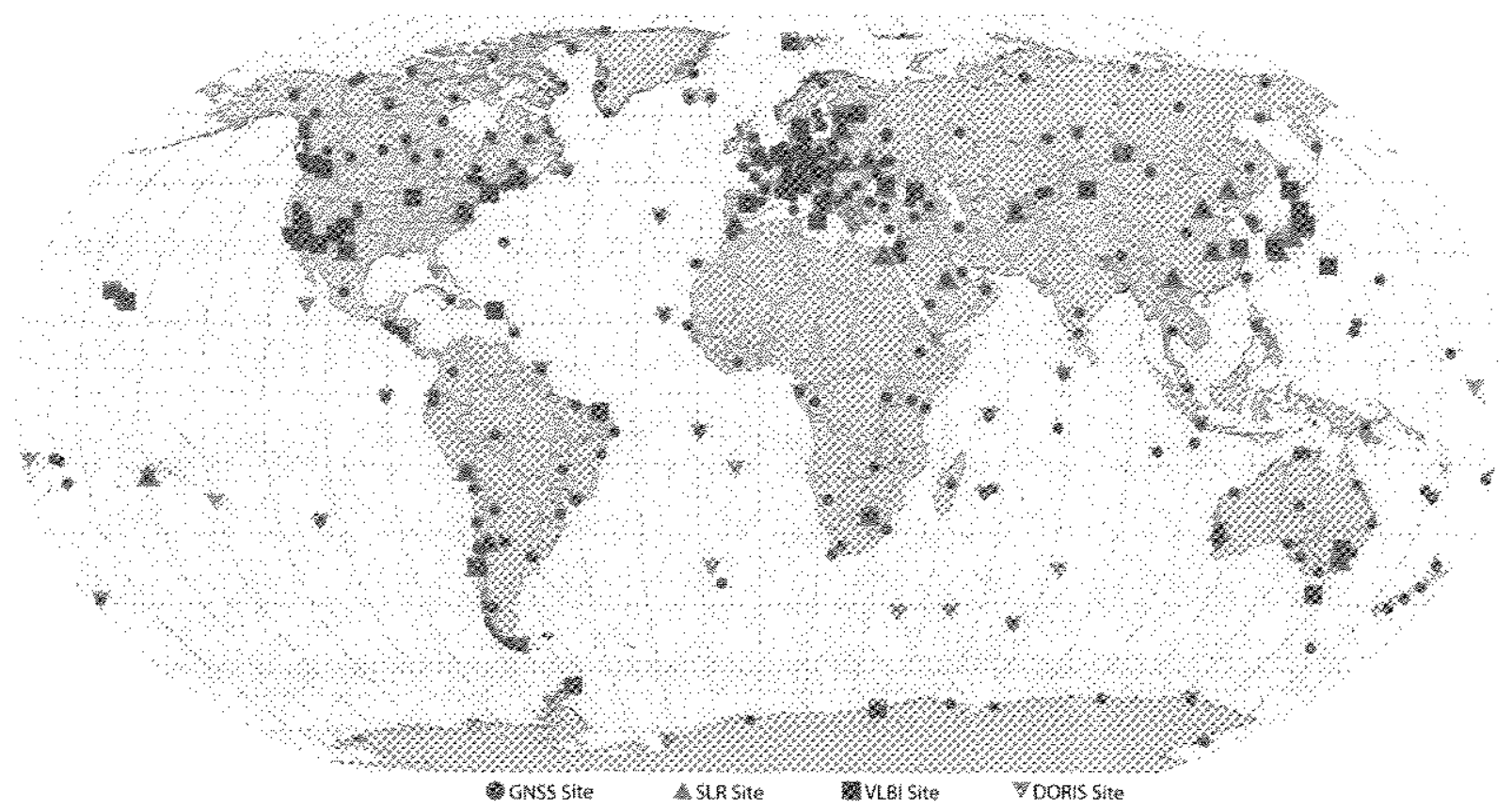

Fig. 2. Today's (September 2009) global network of geodetic observing sites inchudes 57 DORIS sites, 421 GNSS receivers, 40 laser ranging sites, and 39 VLBI stations and provides the means of determining an accurate and global Terrestrial Reference Frame. The CDDIS provides data from these sites and higher-level data products derived from the data to support a wide range of Earth science research.

conclusion of the CDP efforts, the CDDIS continued to support users of data and products resulting from space geodesy observations.

\subsection{Crustal Dynamics Project}

NASA established the Crustal Dynamics Project in 1979 to apply space methods and technology to advance the scientific understanding of Earth dynamics, tectonophysics, and earthquake mechanisms (Bosworth et al., 1993). The Project used three types of space geodetic techniques in this study: laser ranging to artificial satellites or the moon (SLR and LLR), VLBI, and GPS. Through the lifetime of the Project, the international investigators used these technologies to measure crustal motion between a global network of laser ranging, VLBI, and GPS sites as well as conduct other scientific research such as the determination of more accurate polar motion and UTl.

As part of its data management, the Project designed and implemented a centralized data support system, the Crustal Dynamics Data Information System, or CDDIS. After a yeat of development and testing, the CDDIS began fulloper. ations in September 1982. At its inception, the main purpose of the CDDIS was to store all CDP-related geodetic data products in a central data bank and to maintain information about the archival of these data. Investigators supporting the CDP deposited their results, e.g., baseline and station position analysis, into the CDDIS for use by a larger scientific community. Thus, the CDDIS began as a central facility providing Project users access to data and derived products to facilitate scientific investigation.
The highly successful CDP ended in 1991. NASA sponsored further investigations in these areas through several agency research opportunities, including the Dynamics of the Solid Earth (DOSE) program. The CDDIS continued operation as NASA's archive of space geodesy data and products for DOSE, other NASA investigations, and missions requiring space geodetic techniques to further measurement requirements.

\subsection{International Association of Geodesy}

Starting in the 1990's, the space geodesy community established several technique-specific services, operating as cooperative "federations", through the International Association of Geodesy (IAG, http:/ www iag aig.org/). The IAG advances and coordinates international collaboration to foster scientific research in geodesy. In 1992, the International GNSS Service (IGS, http//www.igseb.org), formerly known as the International GPS Service, was the first such "service" established under the IAG to provide precise products from a global network of GPS receiv" ers that would further research in Earth science, multidisciplinary applications, and education (Dow et al., 2008). The IGS became an example for the communities within the other techniques to create additional services: the International Laser Ranging Service (ILRS, http:// ins ggsfenusa.gov) (Pearman et al., 2002), the International VLBI Service for Geodesy and Astrometry (IVS, httw:// ivsec.gsfenasa.gov) (Schliter and Behrend, 2007), and the International DORIS Service (IDS, http://wwwidsdoris.org) (Tavennier et al., 2006). 
The IAG services not only provide data and products on an operational basis to their respective geodesy analysts but also to a broader, interdisciplinary scientific community. These services are examples of a successful model of community management, where they develop service-related standards/conventions, self-regulate, monitor performance throughout the various levels of operation, and define and deliver products using pre-determined schedules. Each group is guided by Terms of Reference, which describes the vision, objectives, and structure of the service and defines the data and products delivered by its components. Standards, both technique-specific and cross-discipline, in data and product generation are utilized throughout all levels in each of the services. The services have developed sets of products using standard models and algorithms that ensure consistency over time. They deliver these data and derived products on an operational basis to geodesy analysts as well as a broader scientific community, monitoring performance during the delivery process. The strong cooperation of the many international organizations in these federations is the main reason the services have been so successful, leveraging their respective limited resources to all levels of service operation. The services also contribute to the activities of the International Earth Rotation and Reference Systems Service (IERS, http:/www,iers.org) for the realization and maintenance of the ITRF (htp:/itrfensg.ign.fr/) (Altamimi et al, 2007). The CDDIS successtully proposed to each service's Call for Participation and was selected as a primary, or global, data center supporting the infrastructure and user communities for the IGS, ILRS, IVS, and IDS.

\subsection{Global Geodetic Observing System}

In mid-2003, the LAG established GGOS, the Global Geodetic Observing System (Plag and Peariman, 2009) as a project to foster cooperation among the geometric services of the IAG and to promote outreach and education to a broad user community on the importance of the geodetic infrastructure to many Earth science applications. GGOS, recently promoted to a component of the $I A G$, works to integrate the geodetic techniques to ensure longterm monitoring of Earth processes, including global change research. Distribution of data and products for the generation of GGOS combination products will be accomplished through the data flow paths developed by the $I A G$ services forming the underlying structure of GGOS. Access to data and products generated by these services will continue to be provided through the services, either directly or via a GGOS portal. This portal will facilitate access to GGOS products and provide a way to view the underlying, dedicated information systems developed by the IAG's contributing services. The CDDIS supports GGOS as an essential archive for the geometric services and will contribute to the GGOS portal by implementing systems to provide uniform access to a combined set of geodetic services' information as well as technique-specific information systems.
2.4. NASA'S Earth Observing System Data and Information System

In late 2007, funding support for the CDDIS transitioned from the science research area within NASA to the Earth Observing System Data and Information System (EOSDIS) (http:/www nasadacs,eos.nasa.gov). EOSDIS is responsible for the processing, archiving, and distribution of Earth science data sets, providing tools to facilitate use of these data, and ensuring that these data are available to the public to study Earth processes from space in order to meet the needs of the global community. In addition to managing the seience systems, EOSDIS supports 12 data centers in the U.S. who each serve a specific Earth system science discipline. As one of these EOSDIS data centers, the CDDIS cooperates with other groups in support of NASA's Earth science goals. This activity includes implementation of metadata standards that will eventually permit discovery of CDDIS archive content by researchers outside the existing user base. Thus, the CDDIS will have the opportunity to promote use of its data and products to a broader scientific community.

\section{Data management support of a global space geodesy infrastructure}

Today, the geometric services (i.e., the IDS, IGS, ILRS, and IVS) established within the IAG constitute the primary user community for the CDDIS. An essential element to the operation of all of the IAG's international scientific services is their information system and archive components. These archives are the central source of data for the services" analysis communities as well as those products generated by the analysis centers for use by a broader user community. The CDDIS serves as the single data center resource from which the data from all these networks, and the resulting products derived from their data, may be accessed.

Each of the IAG's geometric services makes use of a similar, distributed data flow structure (shown in Fig. 3) for the transmission of information, data, and derived products from the observing stations to the user community. The structure for the services can be divided into the following components: Network Stations, Data Centers, Analysis Centers, Analysis Center Coordinators, a Coordinating Center, and a Governing Body. Participants in these service activities collaborate at all levels to ensure consistency and timely delivery of data and products. Table 3 provides a high-level summary of the data and analysis results that are produced by the services and available from the CDDIS archive.

\subsection{Networks}

The global space geodesy network of DORIS, GNSS, SLR/LLR, and VLBI sites (see Fug. 2) is largely the result 


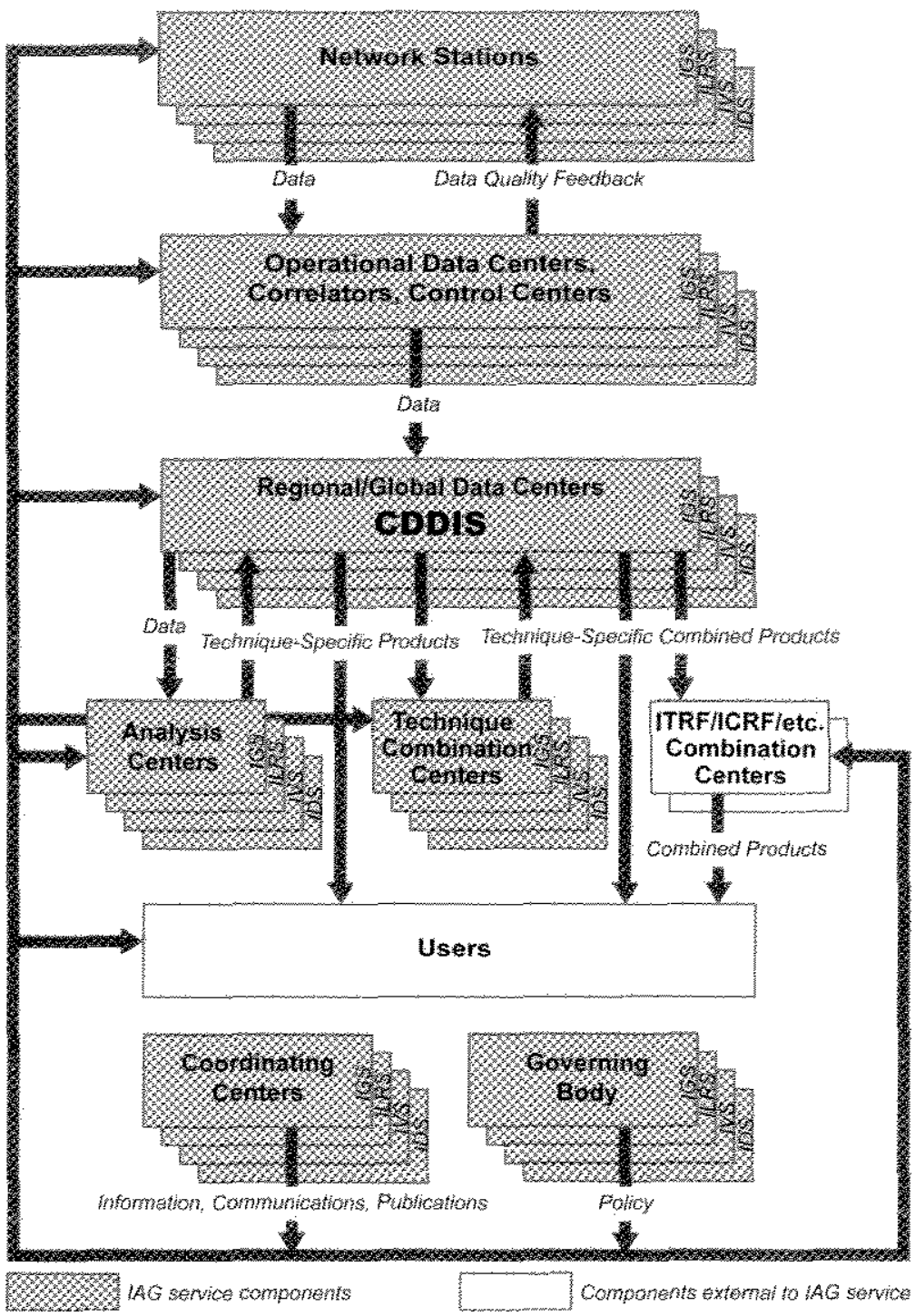

Fig. 3. Each of the IAG services (IDS, IGS, ILRS, and WVS) operates with a similar component structure for transferring data, products and information from station to user. The CDDIS is the single global data system that supports all of the geodetic services and thus provides an integrated approach to serving data and products to the international community and the analysts responsible for generation Earth system products.

of the international collaborations fostered through the IAG services. This network consists of over 650 instruments at over 400 sites, many supporting more than one of these techniques (called co-located sites). These stations track continuously (or using pre-determined schedules as is the case of VLBI), translate data into technique-specific and service standard data formats, and then transmit these data in a timely fashion, typically through electronic means (or, in the case of DORIS, the measurements are made at the satellites and downlinked to a control center), to the data centers. The data are transmitted through the various levels shown in Fig. 3 to ultimately arrive at the analysis centers and general user community.

\subsection{Data centers}

The IAG services utilize a multi-level, herarchical data center structure to efficiently provide data to the user community. For the IGS, MLRS, and IVS, operational data centers (or correlators, in the case of VLBI) have direct contact with the network stations and download their data in a timely fashion (e.g., sub-hourly, hourly, or daily). They will reformat data, if not done at the observing station, validate the resulting files using pre-described parameters for data integrity and quality, and then transmit the data to either Regional or Global Data Centers. For the IDS, DORIS measurements are recorded on-board the satellite 
Table 3

Summary of space geodesy data and products awailable in the CDDIS.

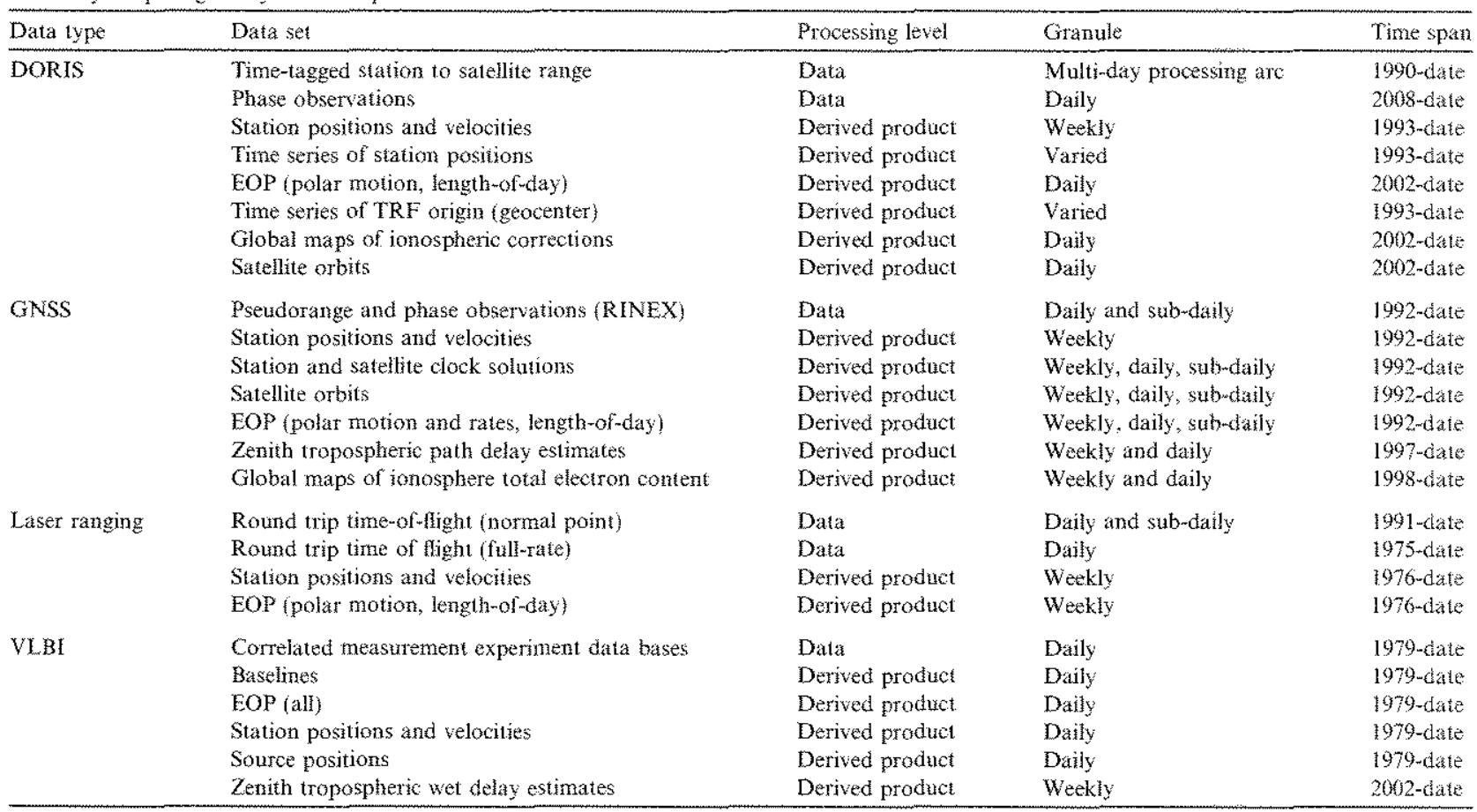

and data are transmitted from the satellite to a centralized control facility for formatting and submission to the Global Data Centers (GDCs). Regional Data Centers (RDCs) collect data for a particular sub-network or geographic region. Typically, data not used by analysts for global studies or used for local/regional research are made available at the regional data center level. GDCs, such as the CDDIS, archive data from a majority of the network stations and interface to either the operational, regional, or other global data centers to populate this archive. These data centers are the main data source for the analysts and the larger user community. RDCs and GDCs also validate the transmitted data to ensure the integrity of the archive and provide ftp and web access to their holdings. Each of the services has identified at least two GDCs to provide for archive security, redundancy to avoid a single point of failure in data archiving, and distribution of user access. The CDDIS is the only GDC supporting all four IAG geometric services.

\subsection{Analysis centers and coordinators}

Using pre determined schedules, each service"s Analysis Centers (ACs) routinely access the GDCs to retrieve the data required to generate those products identified by the service. The ACs then forward these products, such as stam tion positions and Earth orientation parameters (EOPs), to the GDCs for the service-specific Analysis Center Coordinators (ACCs) as well as the user community in general. The ACCs monitor the AC products for quality control and performance evaluation purposes. Furthermore, the ACCs are responsible for the generation of the service's official products through a combination of the individual AC solutions. These standard service products are then made available via the GDCs to users and to other product centers, for example, the IERS, for use in the derivation of higher-level products such as the ITRF.

\subsection{Service coordination and governance.}

The service's Coordinating Center manages the daily operations of the service, facilitates communications at all levels within the service as well as to the external user community, and coordinates other servicemrelated activities. A Governing Body is elected and/or appointed from associate members (representatives from participating organizations as defined in each service's Terms of Reference) and oversees the service, approves its scientific goals, defines a suite of official products and standards, and provides future direction and approval for new activities and products.

\section{CDDIS archive contents and supported data types}

The CDDIS data center is dedicated to supporting the international space geodesy cormmunty, providing straightforward and reliable public access to a variety of data sets, products, and information about these records. Because of the specialized nature of the CDDIS, the system 
Table 4

Basic directory structure for CDDIS archive.

\begin{tabular}{|c|c|c|c|}
\hline Processing lype & \multicolumn{2}{|l|}{ Main directory (Root:ftp://eddis.gsfc.nasa.gov/pub) } & Description \\
\hline $\begin{array}{l}\text { DORIS } \\
\text { Data }\end{array}$ & $\begin{array}{l}\text { /doris/data/SAT } \\
\text { /doris/data/SAT/YYYY/DDD }\end{array}$ & $\begin{array}{l}\text { Dat: } \\
\text { Dat: }\end{array}$ & $\begin{array}{l}\text { ORIS format) by satellite } \\
\text { INEX format) by satellite and time }\end{array}$ \\
\hline Products & /Goris/products/TYPE & IDS & lysis results by product type \\
\hline Other & $\begin{array}{l}\text { /doris/ancillary/quaternions/SAT/YYYY } \\
\text { /doris/cb_mirror } \\
\text { /doris/general }\end{array}$ & $\begin{array}{l}\text { Sate } \\
\text { Mir } \\
\text { Gen }\end{array}$ & $\begin{array}{l}\text { quaternions by satellite and year } \\
\text { f los ftp site } \\
\text { information, data holdings summaries }\end{array}$ \\
\hline $\begin{array}{l}\text { GNSS } \\
\text { Data }\end{array}$ & $\begin{array}{l}\text { /gps/data/daily/YYYY/DDD/YYT } \\
\text { /glonass/data/daify/YYYY/DDD/YYT } \\
\text { /gps/data/hourly/YYYYIDDD/HH } \\
\text { /gps/data/highrate/YYYY/DDD/YYT/HH } \\
\text { /gps/data/satelite/SATNAME/YYYY/DDD } \\
\text { /gps/data/TYPELest/YYYY/DDD }\end{array}$ & $\begin{array}{l}24-\mathrm{h} \\
\text { GLC } \\
1-\mathrm{h} \\
15 \mathrm{~m} \\
24-\mathrm{h} \\
\text { Test }\end{array}$ & $\begin{array}{l}\text { data (GPS+GLONASS) by time } \\
\text { SS only } 24-\mathrm{h} 30-\mathrm{s} \text { data by time } \\
\text { data (GPS+ CLONASS) by time } \\
\text {-s data (GPS+GLONASS) by time } \\
\text { satellite receiver data by satellite and time } \\
\text { a sets by type }\end{array}$ \\
\hline Products & $\begin{array}{l}\text { /gps/products/WWWW } \\
\text { /glonass/products/WWWW } \\
\text { /gps/products/WWWW/reprott } \\
\text { /gps/products/troposphere } \\
\text { /gps/products/ionex/YYYY/DDD } \\
\text { /gps/products/rtpp/WWWW }\end{array}$ & $\begin{array}{l}\text { IGS } \\
\text { IGS } \\
\text { Rep } \\
\text { IGS } \\
\text { IGS } \\
\text { IGS }\end{array}$ & $\begin{array}{l}\text { it, station position, clock, ERP solutions by time } \\
\text { ONASS orbit, station position, clock, ERP solutions by time } \\
\text { ssed IGS orbit, station position, clock, ERP solutions by time } \\
\text { osphere zenith path delay products } \\
\text { sphere total electron content products } \\
\text {-time pilot project clock solutions }\end{array}$ \\
\hline Other & $\begin{array}{l}\text { /gps/data/daily/reports } \\
\text { /glonass/data/daily/reports } \\
\text { /gps/data/hourly/reports } \\
\text { /gps/data/highrate/reports }\end{array}$ & $\begin{array}{l}\text { Rep } \\
\text { Rep } \\
\text { Rep } \\
\text { Rep }\end{array}$ & $\begin{array}{l}\text { of } 24-\mathrm{h} 30-\mathrm{s} \text { data (GPS+GLONASS) holdings } \\
\text { of GLONASS } 24-\mathrm{h} 30-\mathrm{s} \text { data holdings } \\
\text { of } 1 \text {-h } 30 \text {-s data (GPS +GLONASS) holdings } \\
\text { of (GPS+GLONASS) 15-min 1-s data (GPS GLONASS) holdings }\end{array}$ \\
\hline $\begin{array}{l}\text { Laser ranging } \\
\text { Data }\end{array}$ & $\begin{array}{l}\text { /slr/data/npt/SATNAME/YYYY } \\
\text { /str/data/npt/allsaU/YYYY } \\
\text { /str/data/nptcrd/SATNAME/YYYY } \\
\text { /slr/data/SATNAMEIYYYY/daily/SSSS } \\
\text { /slr/data/fr/SATNAME/YYYY } \\
\text { /sir/data/fr_crd/SATNAME/YYYY }\end{array}$ & $\begin{array}{l}\text { Nor } \\
\text { Nor } \\
\text { Nor } \\
\text { Full } \\
\text { Full } \\
\text { Full }\end{array}$ & $\begin{array}{l}\text { point data (LRS format) by satellite and time } \\
\text { point data (ILRS format) for all satellites by time } \\
\text { point data (CRD format) by satellite and time } \\
\text { data (ILRS format) by satellite, time, and station } \\
\text { data (ILRS format) by satellite and time } \\
\text { data (CRD format) by satellite and time }\end{array}$ \\
\hline Products & $\begin{array}{l}\text { /sir/products/pos+eop/YYMMDD } \\
\text { /slr/epf_predicts/YYYY/SATNAME } \\
\text { /slr/cpr_predicts/current }\end{array}$ & $\begin{array}{l}\text { ILR } \\
\text { Sate } \\
\text { Curr }\end{array}$ & $\begin{array}{l}\text { tion position and EOP solutions by time } \\
\text { prediction files by date and satellite } \\
\text { satellite prediction files }\end{array}$ \\
\hline Other & $/ \mathrm{sir} /$ data/reports & Dat: & ding reports \\
\hline $\begin{array}{l}\text { VLBI } \\
\text { Data }\end{array}$ & $\begin{array}{l}\text { /vibi/ivsdata/db/YYYY } \\
/ \text { /ofbi/ivsdata/ngs/YYYY }\end{array}$ & $\begin{array}{l}\text { Exp } \\
\text { Exp }\end{array}$ & $\begin{array}{l}\text { ent databases (dbs format) by time } \\
\text { ent databases (NGS card format) by time }\end{array}$ \\
\hline Products & $\begin{array}{l}\text { /vlbi/ivsproducts } \\
\text { /vibi/ivsproducts/iers- YYYYY } \\
\text { /vlbi/ivsproducts/pilot- } Y Y Y Y\end{array}$ & $\begin{array}{l}\text { rVs } \\
\text { rVs } \\
\text { IVs }\end{array}$ & $\begin{array}{l}\text { ysis by type } \\
\text { ial IERS analysis by time } \\
\text { project analysis by time }\end{array}$ \\
\hline Other & $\begin{array}{l}\text { /vlbi/ivscontrol } \\
/ \mathrm{vbi} / \text { ivsdata/aux } \\
/ \mathrm{vlbi} / \text { ivisdocuments } \\
\text { /vibi/dserver }\end{array}$ & $\begin{array}{l}\text { Gen } \\
\text { Expe } \\
\text { IVS } \\
\text { Files }\end{array}$ & $\begin{array}{l}\text { IVS information } \\
\text { ent supplementary fles } \\
\text { umentation } \\
\text { asferted by dserver protocol }\end{array}$ \\
\hline $\begin{array}{l}\text { Directory structu } \\
\text { Code }\end{array}$ & $\begin{array}{l}\text { and file numing definitions } \\
\text { Description. }\end{array}$ & Code & Deseription \\
\hline DD & Two-digit day of month $(01,02, \ldots, 31)$ & $\mathrm{T}$ & $\begin{array}{l}\text { RINEX fle type }(D=\text { Hatanaka compact observation, } \\
G=\text { GLONASS broadcast ephemeris, } M=\text { meteorological, } \\
N=\text { GPS broadcast ephemeris, } O=\text { obseryation, } S=\text { observation } \\
\text { summary }\end{array}$ \\
\hline DDD & Three-digit day of year $(001,002, \ldots, 366)$ & WWWW & Four-digit GPS week number $(0649,0650, \ldots)$ \\
\hline $\mathrm{HH}$ & Hour of day $(00,01, \ldots, 24)$ & YY & Last two digits of year $(76,77, \ldots, 09)$ \\
\hline $\mathrm{MM}$ & Two-digit month $(01,02, \ldots, 12)$ & YYYY & Four-digit year \\
\hline $\begin{array}{l}\text { SATNAME } \\
\text { SSSS }\end{array}$ & $\begin{array}{l}\text { Satellite name (lageosl, gracea, etc) } \\
\text { Four-digit station idenification number }\end{array}$ & \# & Sequence/version number \\
\hline
\end{tabular}


can be easily modified to accommodate new data sets required to satisfy new user requirements.

An online directory structure of the CDDIS archive has been created to organize files by technique (e.g., DORIS, GNSS, laser ranging, and VLBI) as listed in Table 1 . The contents of the CDDIS online archive supporting these main technique-specific data types can be divided into four major categories:

- Observation data.

- Products derived from the observation data.

- Information about the data and products that aids in their use.

- Metadata, or "data about data", extracted from the observation data and derived products.

The following sections describe each of these main space geodetic data types and their derived products in more detail, including information about metadata and data access. Descriptions of the directory structures and file naming conventions used at the CDDIS are included; detailed structures are given in Table 4.

All data sets, products, and extracted metadata are accessible to scientists through ftp and the web; general information about each data set is accessible via the web. Data and derived products are generally stored in compressed format (using UNIX compression algorithms) with directory names and files utilizing a lowercase naming convention. Descriptive files and data holding reports are typically available in uncompressed text files.

\subsection{DORIS}

DORIS is a dual-frequency Doppler system developed by the Centre National d'Etudes Spatiales (CNES), and partners the Institut Géographique National (IGN) and the Groupe de Recherche de Géodésie Spatiale (GRGS) (Tavernier et al, 2003). The technology was included as a probatory experiment on SPOT-2 in 1990. Since that time, DORIS has played a key role in precision orbit determination (POD) for several current and past missions (additional satellites in the SPOT series, TOPEX/Poseidon, Jason-1/-2, Envisat).

The DORIS receiver on-board the orbiting satellite tracks the dual-frequency radio signals transmitted by a network of ground beacons and generates the DORIS data. A measurement is made of either the Doppler shift, for the first and second generation receivers, or absolute phase, for the new generation DGXX receiver (Auriol and Tourain, submitued for publication). These data are then downloaded from the satellite to a central processing facility. This uplink capability allows for a well distributed network, which is not reliant upon extensive infrastructure at the observing stations as is often necessary with other space geodetic techniques. The current DORIS network consists of 57 beacons (see Fig. 1 for an example site configuration and Fig. 2 for site locations).
The IDS GDCs, which include the CDDIS, utilize a common archive structure and file naming convention. These standards are formalized through discussions between the data centers and the IDS Central Bureau and are described at: http:/wwwids ioris.org/hml/analy. sis_coord/documents/struct do.html.

\subsubsection{DORIS data}

DORIS data records contain a time-tagged range-rate measurement with associated ancillary information. The data records also contain information about any corrections that may have been applied during the processing phase, such as for the ionosphere, troposphere, and satellite center of mass, among others. Furthermore, meteorological measurements (e.g., temperature, relative humidity, ground pressure) recorded by instruments colocated with the ground-based beacons are included with the DORIS data and can be used to determine the tropospheric correction. Data for missions prior to Jason-2 used a DORIS-specific format; these files contain multiple days of data corresponding to the specific satellite's processing cycle. The Jason-2 mission utilizes a new multi-channel DORIS receiver (Tavermier et al., 2006), which is capable of tracking up to seven beacons simultaneously; future DORIS-equipped missions will also utilize this model. This instrument provides both Doppler and phase observations; data from this model are archived in both multi-day DORIS-formatted files and daily fles in DORIS Receiver Independent Exchange (RNEX) format respectively.

The CDDIS, in its role as a GDC in the IDS (Noll and Soudarin, 2006 ), archives data from all missions carrying the DORIS instrument. As of 2009 , there are six operational missions: SPOT-2, -4 , and -5 , Jason -1 and -2 , and Envisat. The archive also contains data from past missions (SPOT-3 and TOPEX/Poseidon). The IDS network will track future DORIS-equipped missions, including Cryom sat-2 (2009), SARAL/AltiKa (2010), HY-2A (2010), the Sentinel series (satellites $-A,-B,-C$, and $-D$, starting in 2012), etc., and thus their data will also be archived at the CDDIS (Wills al., 2010). The current network of 57 stations provides between 1.5 million and 4.7 million observations per satellite each year. Data from altimetry missions (e.g., Jason-1 and -2 , Envisat) are delivered to the data centers in files by are (typically $6-10$ days per file); data from the SPOT satellites are archived in files by cycle (usually 10 days per file). These multimday files of DORIS data average $2.5 \ldots 5$ Mbytes in size and are avalable within 30 days following the end of the observation period; daily data files are typically 2.3 Mbytes in size and are available with a one day delay. Thus, a year's worth of DORIS data from a single satellite averages between 210 and 800 Mbytes, depending on the data format (the new multi-channel receiver allows for more observations thus yielding larger data files). DORIS data are found on the CDDIS server in subdirectories by satellite, for multimay files in the DORIS format, and directories by satellite and time for daily files. 


\subsubsection{DORIS products}

The CDDIS provides public access to DORIS data for derivation of a variety of products; the IDS analysis centers retrieve these data to generate products as defined by the service's analysis coordinator and approved by the Governing Board. Products derived from these DORIS data include precise satellite ephemerides, station positions and velocities (input to the derivation of the ITRF), time series of station coordinates, EOP (polar motion, lengthmof-day), and time derivatives of vertical Total Electron Content (TEC) (Willis et al, 2010). The IDS Analysis Coordinator oversees the combination of the individual $\mathrm{AC}$ solutions, e.g., station positions and velocities. The format and time span of the products varies by product type.

The IDS ACs provide solutions containing DORIS station positions on a weekly basis (Wills et al. 2005) in SIN. EX (Software Independent Exchange format) format (Blewitt et al., 1995); these products represent the IDS contribution to the ITRF and are the primary product generated by the ACs. The time series solutions include daily values of the EOPs. In addition, the time series of station coordinate solutions are available for selected $\mathrm{AC}$ solutions in the STCD (STation Coordinate Difference) format; this format provides Cartesian and ellipsoid coordinate determinations and their formal errors allowing for the generation of point position time evolution plots (Noll and Soudarin, 2006). Other IDS AC products available include cumulative solutions of station velocities and positions at a reference epoch, geocenter determinations, EOPs, and satellite orbits. The DORIS data processing group generates ionospheric correction values from DORIS measurements and makes these derived products available through the IDS data centers, including the CDDIS. Text fles containing descriptions of the solution, models, processing strategy, etc. used in the derivation of the products are stored with submitted IDS analysis center solution files. The archive of IDS products is organized in subdirectories by product type (e.g., time series of station positions, EOP values, orbits, etc.).

\subsubsection{Other DORIS information}

Reports summarizing the current contents of the DORIS data archive are generated nightly from the metadata extracted during the data archival process; these reports are available within the CDDIS DORIS data subdirectories. These summaries consist of one fle per satellite and list the start and end date for each DORIS data file in the archive. Other files summarize the number of observations by satellite and by satellite and station on a yearly basis. For data center backup purposes, the CDDIS stores a mirror of the contents of the IDS Web site, including initial station positions, satellite configuration files, DORISrelated mail messages, and data and product format documentation. The CDDIS Web site (particularly,

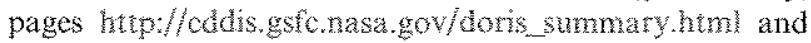
http:/cddis.gstenasa.gov/doris_atasum.html) provides general information about DORIS and the data and product flles available from the data system.

In late 2009 , files containing Jason-1 and -2 satellite attitude information will be made available at the IDS data centers, including the CDDIS. Two types of fles will be available for each satellite: attitude quaternions for the body of the spacecraft and solar panel angular positions. The files will be delivered daily and will contain $28 \mathrm{~h}$ of data, with $2 \mathrm{~h}$ overlapping between consecutive files. Analysts can use these files to determine satellite orientation and attitude information for processing DORIS data.

\subsection{GNSS}

Global Navigation Satellite Systems (GNSSs), such as the U.S. GPS, the Russian GLONASS, and the European Galileo system, provide autonomous geo-spatial positioning with global coverage. Ground (or space-based) receivers collect the signals from orbiting satellites to determine their location in three dimensions and calculate precise time. These receivers detect, decode, and process both pseudorange (code) and phase transmitted by the GNSS satellites. The satellites transmit the ranging codes on two radiofrequency carriers, allowing the locations of GNSS receivers to be determined with varying degrees of accuracy, depending on the type of receiver and post-processing of the data.

The CDDIS supports GNSS data and product archiving for the International GNSS Service (IGS) as one of four GDCs. In this capacity, the CDDIS provides online access to the GNSS data generated by the IGS network as well as the IGS core, working group, and pilot project products derived from these data (Noll et al., 2009).

\subsubsection{GNSS data}

The GNSS data consist of the receiver's observation data, the broadcast orbit information of the tracked satellites, and supporting data, such as meteorological parame. ters, collected from co-located instruments. Currently, the IGS network consists of over 420 globally distributed stations (see Fig. 2), equipped with geodetic-quality receivers (see Fig. 1 for an example GNSS antenna configuration) that track the GPS satellite constellation; a subset of this network, about 100 receivers, are capable of tracking both GPS and GLONASS satellite signals. The GNSS receivers collect the pseudorange (or code) and phase signals on transmitted frequencies and store the data in manufacturer-dependent formats In addition, broadcast ephemeris messages from a majority of the stations and data from coincident meteorological instruments at a smaller subset of sites are collected in separate files.

4.2.1.1. GNSS obsemation and navigation data. The CDDIS archives IGS GNSS data in three forms based on temporal coverage: daily, hourly, and sub-hourly. The daily data files contain $24-\mathrm{h}$ of data at a 30 -s sampling interval, spanning 00:00:00 to 23:59:30 in GPS time. Daily 
files are transmitted from the stations to data centers following the end of the UTC day (ideally within minutes after the end of the day). Hourly files contain a single hour of 30 -s sampled data; thus there are nominally 24 hourly files per site per day. These data files are transmitted to the CDDIS within minutes following the end of the hour. The final type of GNSS data consists of fles containing $15 \mathrm{~min}$ of GNSS data sampled at a 1 -s rate. These "highrate" data fles nominally start at $00,15,30$, and $45 \mathrm{~min}$ within each hour and are transmitted within minutes following the end of these intervals; there are ideally 96 files of high-rate data per site each day. These categories of GNSS data (daily, hourly, high-rate) are useful to the derm ivation of different products constrained by varying prom duction schedules. In addition, not all sites provide hourly and high-rate data to the IGS.

Daily, hourly, and sub-hourly high-rate GNSS data for all sites are archived in type-specific flles: observation, containing the code and phase measurements, navigation (either GPS or GLONASS), containing the broadcast ephemeris, and meteorological, containing temperature, pressure, and humidity values recorded by co-located instruments. These data types, regardless of sampling rate and time span, are stored in a common ASCII format, the Receiver INdependent EXchange (RINEX) format (Gurtner et al., 1989; Gurtner, 1994). Prior to release to CDDIS, data in receiver-specific formats are translated into RINEX; the observation data are also software com. pressed using algorithms to eliminate redundant information, recording only variations and reducing the digits of data by taking differences over adjacent epochs (Hatanaka, 1996). The resulting compacted observation file, when further compressed using UNIX compression algorithms, is reduced in size by a factor of eight, allowing for not only a decrease in storage requirements but also in network file transfer times. Users of these data must use freely available, specialized software to reverse the compaction process and retrieve the full observation file.

The CDDIS creates daily broadcast ephemeris files from the input files transmitted by the stations; these fles (one for GPS, a second for GLONASS) contain the unique GPS or GLONASS satellite ephemeris messages for each day. A similar file is created at the start of the UTC day and updated on an hourly basis from the hourly broadcast navigation files. Users can therefore download a single file each day or hour, which contains all broadcast ephemeris messages required for postmprocessing.

GNSS data are collected in files by site and time span (daily, hourly, sub-hourly). The CDDIS GNSS data archive is organized by these temporal subcategories using slightly different directory structures as shown in Table 4. For daily data, these site files are stored in directories by year, day of year, and content (e.g., observation, navigation, meteorological, or data quality summary). A day of GNSS data from a single site averages 1.65 Mbytes for a total of 225 Gbytes/year for a 400 -site network. During recent years, the CDDIS has archived approximately
$125 \mathrm{~K}$ GNSS station days of data per year. Data in files containing $1 \mathrm{~h}$ of 30 -s data are avallable in subdirectories by year, day of year, and hour of day; all types of RINEX data are stored in these hourly subdirectories. Since sta. tions supply fles containing the full $24 \mathrm{~h}$ of data at the conclusion of the observation day, the individual hourly files are not required and are removed from the archive after a period of time. High-rate, 1-s GNSS data, stored in files spanning 15-min, are found in subdirectories by year, day of year, file type, and hour. The data from each high-rate site is approximately 9 Mbytes per day or over 400 Gbytes per year.

4.2.1.2. Other GNSS data. The CDDIS supports the user community by providing access to data from special programs, such as data from receivers tracking new signals (e.g., for GPS, the civil signal on L2, L.2C and the new civil frequency, L5) or data in new formats (e.g., data in version 3 of the RINEX format, data generated from software receivers). The structure of the CDDIS archive is relatively simple to modify in order to accommodate these test data; the CDDIS strives to facilitate scientific research by providing access to new data types and formats.

The CDDIS makes GPS data available from flight receivers on-board selected LEO satellites. These data can be used for precise orbit determination; multiple satellites equipped with GNSS receivers could one day form a space network of orbiting GPS receivers to extend the ground GNSS network that would lead to the development of other applications for these data. The GPS flight receiver data are also archived in RINEX format and are available in subdirectories by satellite, year, and day of year. Currently, the CDDIS archive contains on-board GPS satellite data from the CHAMP, ICESat, Jason-1, and SAC-C missions. The CDDIS plans to expand this archive of satellitebased GPS data in the near future to include additional satellites as well as complete the archive of data from currently supported missions.

The CDDIS archive also supports specialized experiments and tracking campaigns. Prior to the start of the IGS, most available GPS data resulted from specialized campaigns of days or weeks in duration. The data from these experiments are stored in subdirectories by experiment and time period.

\subsubsection{GNSS products}

A wide range of products derived from GNSS cata archived in the CDDIS are generated and submitted by the IGS ACs and Associate Analysis Centers (AACs). The "core" or operational IGS products include precise GNSS (GPS and GLONASS) satellite ephemerides, positions and velocities of stations in the global GNSS network, EOPs (polar motion and rates, length-of-day), and station and satellite clock solutions. Other products derived from the CDDIS GNSS data holdings, such as troposphere Zenith Path Delay (ZPD) estimates (both dry and wet components) and global ionosphere maps, are submitted 
by IGS AACs on a routine basis. These products are typically the result of studies conducted within IGS Working Groups or Pilot Projects.

4.2.2.1. Operational IGS products. Individual ACs and AACs submit derived products on pre-determined sched ules, e.g., sub-daily, daily, or weekly, to the IGS GDCs. The designated IGS Analysis Center Coordinator (ACC) for each product retrieves these solutions and produces a combined product, which is then in turn archived at the CDDIS and the other IGS GDCs (Noll et al., 2009). These combination solutions are considered the official IGS products. IGS orbit and clock combination solutions are available in three forms: ultra-rapid, rapid, and final (Griffiths and Ray, 2009). The ACC provides an ultra-rapid product, useful for real-time and near real-time applications, at regular intervals four times per day; the ultra-rapid solution includes both observed and predicted satellite orbits and clocks. The rapid orbit and clock combination is a daily solution available approximately $17 \mathrm{~h}$ after the end of the previous UTC day. The final, and most consistent and highest quality IGS solutions, consists of daily orbit and clock files, generated on a weekly basis approximately 13 days after the end of the solution week. All orbit and clock solution files utilize the Extended Standard Product-3 (SP3c) format (Hilla, 2002).

The IGS Reference Frame Coordinator (RFC) also produces a weekly solution consisting of combined station positions and velocities, daily length of-day (LOD) and $X, Y$ pole positions and rates, and geocenter positions; the RFC derives these products from the individual weekly input solutions from the contributing IGS ACs (Ferland and Piraszewski, 2009). These weekly combination solutions provide the basis for the IGS contribution to the TRF. The weekly files are archived at the CDDIS in SINEX format.

All operational IGS GNSS products (i.e., orbits, station positions, EOP, clock solutions) are avallable in subdirectories by GPS week, Other IGS products, developed through working group or pilot project activities, are stored using separate directory structures. These products include troposphere ZPD estimates, along with statistics about the product, derived from GNSS measurements and ionosphere vertical total electron content maps (rapid and final) for climate research and atmospheric studies. Combined clock solutions derived in real-time from AACs using data from the IGS network of real-time data-streaming sites are also avallable for studies to compare the quality of the real-time products with the IGS ultramrapid, rapid, and final clock products.

4.2.2.2. Reprocessed /GS products. Beginning in the fall of 2008 , the CDDIS supported the first IGS reprocessing effort, archiving new solutions generated by contributing ACs. The ACs remanalyzed the rich historical IGS data set (from 1994 to 2007) with the goal to produce a fully consistent set of products utilizing the most recent models and updated processing strategies (Ray and Griffiths, 2009; Ferland, 2009). To begin this project, the CDDIS inventoried current data holdings and made efforts to locate and capture missing data sets in order to aid the ACs in including additional sites in their analyses. The products generated for the reprocessing process include daily GPS orbits and clocks, daily station and satellite clocks, EOPs, and weekly station coordinates and velocities. Until these new solutions are declared the "operational" IGS product, they are archived at the CDDIS in special subdirectories within the GNSS product structure. When the re-analysis activity has been completed, these products will replace the current operational IGS products at the GDCs; the files containing the initial version of the IGS products will be retained at the CDDIS in separate historic subdirectories within the weekly product directory structure. The IGS plans to repeat the re-analysis effort on a periodic basis.

\subsubsection{Other GNSS information}

During the validation process for incoming data, reports summarizing the contents of the data files are generated; metadata are extracted from these files and inserted into a relational database. Daily, weekly, and yearly reports summarizing the current contents of the GNSS data archive, providing spatial and temporal coverage informam tion, are generated nightly from these metadata; these reports are available in the CDDIS GNSS data subdirectories. Files also containing assessments of data quality, timeliness of delivery, and statistics on number of data points, cycle slips, and multipath are updated during the data ingest process for the daily GNSS files. These reports allow users to view a snapshot of data availability and quality in a single daily status file. GNSS data and product holdings and general information are described on the CDDIS Web site at http:/cddis.gsfenasa.gov/gnss summary.html and http//cddis.gsfe.nasa.gov/gnss_datasum.htm:

\subsection{Laser ranging}

In laser ranging, a short-pulse of light generated by a laser is transmitted in a narrow beam to illuminate corner cube retroreffectors on a satellite (satellite laser ranging or SLR) or the Moon (lunar laser ranging or LLR) (Degnan, 1994). The station's (see Fig. I for an example SLR station) telescope collects the return signal and the time-of-flight is measured which is used to determine the range to the satellite to a precision of a few millimeters. Using information about the satellite's orbit, the time-of-fight, and the speed of light, the location of the ranging station can be determined. Today, the SLR network supporting the International Laser Ranging Service (ILRS) consists of over 35 stations (see Fig. 2). This global SLR network tracks over forty satellites equipped with retroreflectors. These satellites fall into four major categories: geodetic (satellites whose main purpose is for space geodesy studies), Earth sensing (satellites whose primary mission is to support Earth science goals; laser ranging is typically used for orbit 
determination), positioning (GNSS satellites that utilize laser ranging for validation of GNSS orbit determination), and experimental (satellites with engineering payloads using laser ranging for a variety of supporting studies). SLR contributes to the determination of static and time. varying coefficients of the Earth's gravity field, total Earth mass, and temporal variations of the observing network origin with the respect to Earth's center of mass (Altamimi, 2009; Gross, 2009; Pavlis, 2009).

\subsubsection{Laser ranging data}

Laser ranging data consist of a distance or range (round-trip, station to satellite and back) and time, together with data correction information such as atmospheric effects, which are to be applied to the data. Raw laser ranges are formatted at the remote station before transmission to operational data centers where the data are translated into the appropriate format. Currently, laser ranging data are available in two forms: original observations (full-rate data) and condensed range observations generated from these original observations collected over several seconds to minutes (normal points).

The ILRS has introduced a new data format, the Consolidated Laser Ranging Data Format (CRD) (Ricklefs, 2008), into service operations (station, data center and analysis center levels). This format can handle all types of laser ranging data (normal point and full-rate) and can accommodate future transponder missions and high-repetition rate laser tracking systems. CRD is a flexible, expandable format with multiple record types. Currently, as testing continues at stations, data centers, and analysis centers, data are available in both the older ILRS and new CRD formats. The ILRS hopes to exclusively use the new CRD format in an operational mode by early 2010 .

4.3.1.1. Normal point data. Laser ranging normal points constitute the primary ILRS data product; they are gener" ated following the conclusion of the laser pass and typically transmitted to data centers within hours. Laser ranging normal points are compressed data using sampling over time based upon a minimum number of data points within the sampling interval. The length of this normal point interval is primarily dependent upon the satellite altitude; lower orbiting satellites have a shorter normal point interval than high-orbit satellites. The current format, known as the ILRS Normal Point format, is an ASCII format containing a header record followed by data records. The header record contains satellite and station designators, general station configuration information, and normal point caleulation parameters. The data records that follow contain laser fre times (in units of $0.1 \mu \mathrm{s}$ ), system delay (picoseconds), bin RMS, meteorological data (pressure, temperature, relative humidity), and number of ranges used in the normal point formation.

ILRS operational data centers forward normal point data to the CDDIS in hourly and daily files by satellite with a typical latency of less than one day following the observations. Each day, the CDDIS updates monthly satellite-specific files containing all normal point data received to date for the month. Daily fles contain all normal point data for each satellite received at the ILRS operational data centers in the previous $24 \mathrm{~h}$ period. Thus, these daily files may contain data spanning several operating days. The monthly files contain all normal point data for each satellite during the month. Daily and monthly normal point data are available from the CDDIS in subdirectories by satellite and year. For users interested in all data received during a particular 24 -h period, a single daily file containing all satellites can be retrieved; this daily file is available from the "allsat" subdirectory within the normal point archive area. Daily normal point files are less than $100 \mathrm{kby}$. tes in size; monthly satellite normal point fles are typically 1-2 Mbytes.

4.3.1.2. Full-rate data. Full-rate data include all valid satellite returns and are thus larger in volume; these data are not routinely provided by all stations in the laser tracking network. Full-rate data are useful for both engineering evaluation and scientific applications (e.g., studying the performance of retroreflectors, discerning satellite signatures, understanding the statistical nature of satellite returns, calibration of satellite targets, validating system quality of laser station co-locations, etc.). Although many of these studies are of an engineering nature, the results have an important impact on the quality of the scientific output. Full-rate data are transmitted to the CDDIS in files containing all data from a station and satellite on a particular day; these daily files range in size from 10 to 100 kbytes. The CDDIS then combines daily files from all stations into a monthly satellite-specific fle; monthly full-rate data files are approximately 10 Mbytes in size. These files are curm rently available in the ILRS full-rate format in subdirectories by satellite and year.

4.3.1.3. Lunar laser ranging data. A subset of the global network is capable of laser ranging to retroreflectors placed on the lunar surface by NASA Apollo and Russia Lunakod missions in the 1969 1973 time period. The CDDIS archive of these data, in LLR-specific formats in early years and ILRS format since 1998, dates back to 1969. In a sense, the Moon and its retroreflectors can be considered another "satellite"; however, not all systems in the ILRS network have lasers powerful enough to reach lunar distances. Today, two of the ILRS stations continue tracking these arrays; additional stations plan to become operational in the near future. Analysis of LLR data provides information about the dynamics and structure of the Moon, its rate of rotation, and orbit, as well as gravitational physics and general relativity studies (Whim and Dickey, 2003 ).

4.3.1.4. LRO laser ranging support In its role as an archive of SLR data, the CDDIS is supporting a laser ranging experiment to an instrument on-board the Lunar Reconnaissance Orbiter (LRO). This experiment uses 
oneway range measurements to the Lunar Orbiter Laser Altimeter (LOLA) instrument from select laser ranging staw tions to determine the satellite's position at sub-meter levels with respect to Earth and the center of the Moon. The oneway laser ranging aspect of the mission will allow for the determination of a more precise orbit than possible with $S$-band tracking data alone. In addition to an archive for the one-way laser ranging data, the CDDIS provides an interface between mission operations activities and the sub-network of the laser ranging sites capable of tracking LRO for various input files required for tracking. General information about the LRO Laser Ranging (LRO-LR) activity is avalable from a Web site hosted by the CDDIS (http://rolr.gsfenasa.gov). Furthermore, the CDDIS provides limited access to a real-time Web site that allows stations to monitor their progress during tracking.

\subsubsection{Laser ranging products}

Products derived from these SLR observations include precise satellite ephemerides, station positions and velocities of sites in the ILRS network, and EOPs (polar motion and rates, length-of-day) (Pearlman et al., 2002).

4.3.2.1. Station positions and EOP. The CDDIS archive of laser ranging products consists of solutions derived in support of the ILRS. Official products as designated by the ILRS include station positions and EOP, dating from the early 1980"s through the present. ACs deliver this weekly station position/EOP product, called "posteop" in the data center directory structure, to the ILRS data centers, including the CDDIS, on a regular basis, typically within 2-3 days following the end of the observation week. The ILRS combination centers retrieve these solutions and produce the combined ILRS A and B solutions (generated by the primary and backup ILRS combination centers, respectively) within four days following the end of this observation week. During 2009, the ILRS ACs and combination centers underwent an extensive reprocessing campaign to provide the official ILRS contribution to the next ITRF solution. This reprocessing effort allowed the ACs to use updated processing methods and models in analyzing the SLR data set, from the early 1980 's through the present. The individual ILRS AC and combination center station position and EOP solutions are archived in weekly subdirectories designated by the end date of the 7-day solution interval.

In addition, dally station position and EOP solutions, with a 1-2 day delay, are currently under development within the ILRS. This product has been designed to provide input to the IERS rapid service and prediction center, which generates EOP solutions for real-time users. Standard ILRS orbit products for a subset of the satellite tracking roster are also under development and evaluation.

4.3.2.2. Satellite orbit predictions. The laser ranging stations require satellite orbit information in order to point their instrument to the correct location and acquire returns from the retroreflectors. Mission operations centers generate these predicted future orbits from calculated ranging data orbits; the files are transmitted to the stations through email or by storing them within data center archives. Predicted orbit information is typically available in dally files and sorted by year and satellite within the CDDIS. The Consolidated Prediction Format (CPF) (Ricklefs, 2008) is now used operationally for satellite predictions within the ILRS; CPF provides orbit data that accurately predict positions and ranges for a large variety of targets in tables of $X, Y$, and $Z$ positions, which can be interpolated for accurate predictions. Unlike its predecessor the Tuned Inter-Range Vector (TIRV) format, the CPF supports many current and future ranging applications, from satellite to lunar to interplanetary transponder targets and can accommodate laser station technology developments, such as high-repetition rate laser systems. The CPF can also include planned maneuver and satellite drag information. This format consists of fixed format header records and free format, space-delimited configuration and data records. SLR stations download these prediction files and coordinate tracking schedules for satellite acquisition. Satellite prediction files are archived on the CDDIS by year and satellite. In addition, stations can retrieve the latest predicted orbit file for all laser tracked satellites in a single subdirectory. These predicted orbit files typically contain orbit information for multiple days and are issued on a daily basis. Predictions for lower orbiting satellites (e.g., $300-500 \mathrm{~km}$ ) are often transmitted several times per day.

\subsubsection{Other SLR information}

Metadata extracted from incoming normal point and full-rate data are utilized to create various summary reports detailing the spatial and temporal coverage of the CDDIS laser ranging data holdings. Anellary information, such as station confguration logs, satellite orbital parameters, station occupation histories and a prioni location information, are provided to aid users in SLR data analysis.

The CDDIS Web site pages htp//cddis,gsfenasa.gov/ in_summary.html and htp//cddis.gsfenasa.gov/sir data. sum.htm give general information about laser ranging and the associated data and product fles available through the CDDIS. The CDDIS also maintains the Web site and archive for the ILRS (http//1rs.gstenasa.gov) as well as those sites created for the international workshops on laser ranging held on a bi-annual basis.

\subsection{VLBI}

VLBI is a geometric technique that measures the difference in time between the arrival of a radio wavefront ema nating from a quasar at two specially equipped antennas. When a large number of these time difference measurements from many quasars are observed with a global net. work of antennas, the VLBI technique can determine the inertial reference frame defined by the quasars as well as 
the distance between observing antennas, and thus the precise positions of these antennas (Schututer and Behrend, 2007). The time difference measurements are precise at the 10-20 picosecond-level and therefore VLBI can determine the relative positions of the antennas to a few millimeters and the quasar positions to $0.05-0.25$ milliarcseconds. Furthermore, these antennas allow analysts to determine the orientation of the Earth in an inertial reference frame.

These globally distributed stations participate in VLBI experiments, typically $24-\mathrm{h}$ sessions, on various pre-determined schedules; single stations contribute from several days per week to several days per year. Because of the close cooperation and correlation required for the VLBI technique, the VLBI observing schedule is coordinated by a central group within the International VLBI Service for Geodesy and Astrometry (IVS). The extent of participation by individual antennas in VLBI is dependent upon many factors, including available observing time tor these activi. ties. The network of IVS and cooperating VLBI stations consists of nearly 40 stations (see Fig. 2); a photo of a typical VLBI antenna is shown in Fig. 1.

\subsubsection{VLBI data}

The raw observables from the participating antennas involved in VLBI experiments of simultaneous measurements are compared, or "correlated", at a central facility (called a correlator). The initial output from this process, consisting of "database" files, is archived; analysis groups add meteorological information and apply theoretical quantities and models to this version, resulting in higher number versions of the database files. Additional informam tion available in these VLBI data files includes calibration data, solar system ephemerides, a priori parameter values, Earth orientation information, partial derivatives, and theoretical delays and rates. All versions are retained at the CDDIS and other IVS data centers for documentation purposes. Each VLBI experiment has separate database files containing $\mathrm{S}$ - and $\mathrm{X}$-band data. This VLBI experiment data consists of the observing site parameters, source information, correlated delay and delay rate between the observing antennas as a function of time, along with meteorological data and system parameters that must be applied to the correlated measurements. The amount of delay necessary to bring the signals from two observing telescopes into time phase is determined. This delay is dependent upon the quasar position relative to the two antennas. When the delay has been determined, the distance between the two telescopes can be calculated.

The VLBI experiments, organized by experimental session and frequency band, are available in two formats, designed for use by different processing packages: binary databases and an ASCII format (NGS card). The NGS card version of the experiment data is created from the last updates made to the databases; they are typically $10-150$ kbytes in size. Experiment files in binary database format range in size from 10 kbytes to 6 Mbytes. The VLBI experiment data are available on the CDDIS in subdirectories by type (db, for database, or ngs) and year.

The CDDIS also makes the raw correlator output files available; these data can be used during processing and analysis of the experiments. These output files are also useful in diagnosing problems that may have been found during the experiment session. The correlator output files, in various VLBI-specific formats, are large, typically 5 Gbytes per file.

\subsubsection{VLBI products}

Products derived from VLBI measurements include the correlated delay and delay rate of simultaneous observations as a function of time, station positions and velocities, positions of quasars (input to the International Celestial Reference Frame, ICRF), EOPs (polar motion and rates, lengthof-day, UT1-UTC and long-term stability of nutation), and troposphere parameters (Schluter and Behrend, 2007). IVS ACs use the VLBI experiment data to derive these products and post them to the CDDIS (and other IVS data centers) using pre-determined schedules. The IVS Analysis Coordinator inputs these products to a combined solution of station positions, which becomes the IVS contribution to the ITRF. All IVS products are found on the CDDIS in subdirectories by product type. Products for special campaigns and projects are stored in dedicated subdirectories.

IVS products are organized by solution type: CRF (source positions), TRF (positions, velocities, and correlations), EOP (UT1 from 1-h intensive, and polar motion, nutation, and UT1 from 24-h sessions), and troposphere Zenith Wet Delays (ZWDs, signal propagation delays due to water vapor in the atmosphere). Files, typically less than 1 Mbyte in size, are stored within these subdirectories by analysis center. Product-specific formats are used, SINEX for station positions and troposphere ZWD, IVS standard for EOP, and IERS standard for CRF.

\subsubsection{Other VLBI information}

As part of its role as an IVS data center, the CDDIS provides access to various auxiliary files needed for conducting VLBI experiments and using VLBI data and products. An "ivscontrol" directory contains text files with archive structure documentation, master VLBI schedules, and IVS participating center code definitions (e.g., station, analysis center, and correlator abbreviations and their definitions). Within the VLBI data subdirectory structure, an auxihary subdirectory contains supplementary files from all VLBI experiments useful in the data analysis process (e.g., station schedules, logs, and correlator reports). Analysis center solution descriptions and other IVS supporting files are available in a documentation subdirectory.

An IVS-internally developed program called dsemer is operational on CDDIS. Several IVS groups use this package for automated fle upload to participating data centers. This program provides reliable data transfer capabilities such as checking for data consistency, relocation of incoming files to their appropriate archive directories, and notification to suppliers of the success or falure of the transfer. 
The CDDIS web pages http//cddis.gsfcnasa.gov/ vlbi_summary.html and http//cddis gsfenasa.gov/nbi datasum.html provide general information about VLBI and the data and product files available on the server.

\subsection{Supporting information and metadata}

In addition to data and their derived products, the CDDIS archive contains diverse supporting information that aid analysts in using these files. This information includes spacecraft and instrument specifications, observation station characteristics and configurations, site co-location details, and analysis center processing methodologies. Analysts require these details to ensure the correct interpretation and quality of the data used to generate products for scientific research. Local station information, such as a priori station coordinates derived from traditional survey measurements, site descriptions, site identification parameters, etc. are provided for all data types.

Metadata describes and provides information about data. They are used to aid in the management and analysis of the archived data and products through understanding their characteristics. The CDDIS file ingest processing of submitted data and derived products extracts metadata from incoming files. The resulting parameters are stored in a relational database. Such metadata includes file name, source, arrival time, observing station identification, spatial and temporal attributes, observed satellite, instrument parameters, etc. At this time, the metadata created at the CDDIS utilizes formats created in house that are data type-specific. Summaries of data holdings are generated daily from these metadata to reflect recently, as well as previously, archived files.

Sharing of metadata between data systems enables a larger user community to discover data sets of interest. The CDDIS provides data, product, and data service descriptions to NASA's Global Change Master Directory (GCMD, http//gemd.nasa.gov), a directory to facilitate global change research, providing scientists with the means to identify data sets and services of interest. The GCMD contains descriptions of data and data services, like the CDDIS, providing links to the sources of these data. Scientists can search GCMD based on a variety of parameters (instrument, scientific area of interest, keyword, etc.), enabling identification and access to a diverse set of Earth science data and services. Users can enter keyword search criteria or free text to enable this search for information. Data set entries are available for the space geodesy data and products archived in the CDDIS. CDDIS participation in the GCMD further publicizes space geodesy data and products, and their global scope, to a wider scientific audience.

\section{CDDIS operations}

The methodology for the CDDIS archive processing has been structured to efficiently support the requirements for the receipt, cataloging, and distribution of data and products for the IAG services, the IDS, IGS, ILRS, and IVS. Space geodesy data and products are delivered to the CDDIS from a variety of international sources through ftp. The contributions from the services arrive on a weekly, daily, hourly, and sub-hourly basis, depending upon the type of data or product. Software developed by the CDDIS automatically peruses incoming data areas, retrieves deposited files, extracts pertinent metadata, verifies content quality (formats and readability), and moves files to the appropriate archive directory location. Fig. 4 shows the current allocation of the CDDIS archive by technique (DORIS, GNSS, laser ranging, VLBI, general metadata); more detail is shown for the GNSS data type. Fig. 5 breaks down the archive contents by processing level (data, product, metadata/supporting information). As can be seen from these two charts, the largest portion of the CDDIS atchive is devoted to the storage of space geodesy data, particularly GNSS data.

\subsection{Archive processing}

The processing activity for augmenting and updating the contents of the CDDIS archive can be divided into several structural components: deposit, operations, download, and supplementary support. This division by function allows for efficient processing as well as security in system operations.

Suppliers of content for the archive, such as operational centers for the data from the networks of tracking stations, cooperating data centers, and analysis centers, transfer their data and/or product files to the CDDIS deposit or "incoming" disk location using ftp. The underlying user accounts to receive these contributions have limited privileges, allowing data and product providers to deposit files but not retrieve files from these disk areas. These deposit areas on the CDDIS servers are not viewable to the general user community; users of these restricted accounts have their access confined to their "home" directory structures. In a few cases, the CDDIS will retrieve files for the archive from data/product sources. The CDDIS receives (or retrieves) approximately 90 Gbytes (over one million files) of data and derived products during a typical month of file ingest operations, which totals over one Tbyte per year of new information for the online archive. This yearly ingest. rate will increase as new stations are added to the networks and new products are developed by the services.

All processing of these incoming files takes place in the CDDIS operations area, which is accessible to internal users only. Software has been developed to scan the deposit directories on pre-determined schedules dependent upon the type of incoming files. Once new files are detected, the software copies the files to temporary locations where their contents are validated for readability and integrity (format and content) and metadata are extracted and loaded into a relational database. Depending upon the type of data, these metadata may also be archived in files with the data or used to create/update files that summarize the 
current data holdings. Once checked for validity, the incoming files are moved to the public download area in directory locations dependent upon data type and temporal parameters. The entire incoming file handling process, from receipt to archive, is designed to minimize the time required to make the incoming data and products available to the end user.

The download area, i.e., the CDDIS public archive, is openly accessible to the scientific community through anonymous ftp and the web. It is the repository for all valid files provided by the operational data centers, analysis centers, and analysis center coordinators. The structure of the archive follows conventions established within the services and thus is data type (i.e., DORIS, GNSS, SLR, or VLBI) dependent. Within each data type-specific directory, the structure is further subdivided by processing level (i.e., data, product, or supporting information), measurement epoch (e.g., year and day of year, etc.), and file type (e.g., GNSS observation vs. navigation data, SLR normal point vs. full-rate data, etc.).

A final portion of the CDDIS archive is devoted to metadata and supporting information, particularly files summarizing the contents of the download area. As in the user file download area, these fles are tabulated by data type and fle type. Files containing summary information, such as atvailable data holdings, temporal and spatial coverage, data quality, and statistics, are available to aid the user in data discovery. Additional fles reflect the timeliness of the incoming files. The CDDIS utilizes a relational database for storage of metadata from the DORIS, GNSS, laser ranging and VLBI data sets. Automated queries to this database produce these summary files.

The CDDIS makes use of a dedicated server system for delivery, processing, and archive operations. The archive

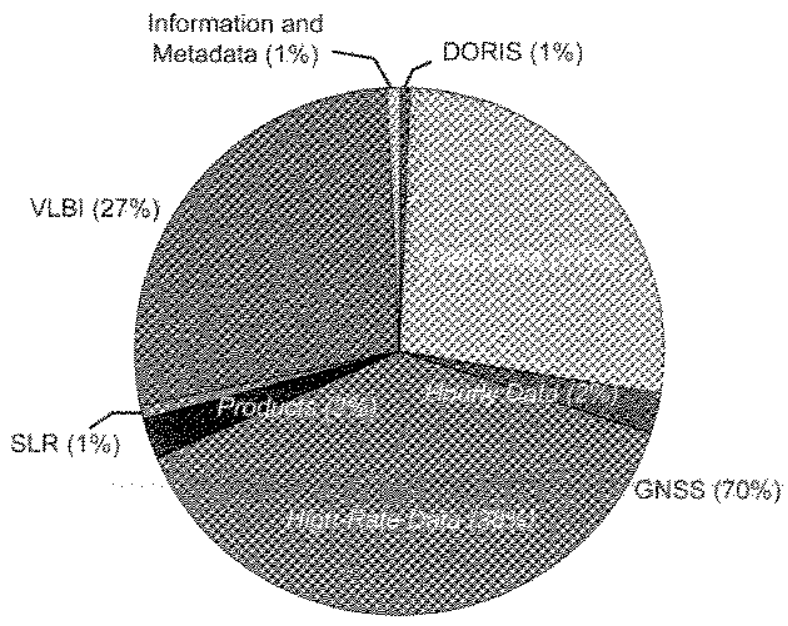

Fig. 4. The breakdown of the contents of the CDDIS online archive by data type as of September 2009. The majority of the online storage is devoted to the archive of GNSS data (as shown in the further breakdown for GNSS) and "xaw" VLBI data (measurements taken by VLBH instruments used as input to the correlators for generation of the final, multi-station, correlated VLBl experiment fifes).

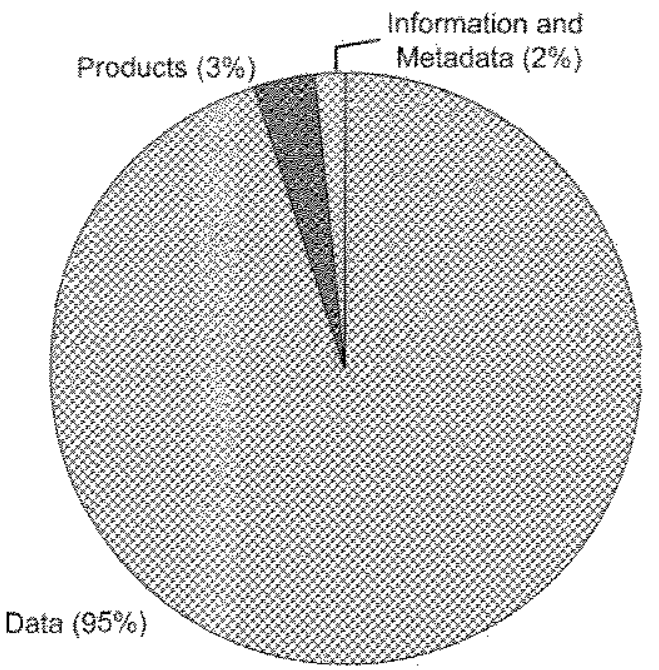

Fyg. 3. The division of the CDDIS arohive by processing level/content eype as of September 2009. The major portion of the CDDIS ontue storage is devoted to the archive of DORIS, GNSS, laser ranging, and VLBI data; derived products constitute a much smaller portion of the storage requirements.

functions for incoming and outgoing (i.e., ftp) are currently implemented on a single server but will be split onto distributed servers in a future configuration. The current archive is housed on RAID disk arrays, of which approximately five terabytes are currently in use.

\subsection{User support}

Charts summarizing the usage metrics of the CDDIS archive are given in Figs. 6 8. Fig. 6 shows the distribution of files by data/product type, with a further breakdown for

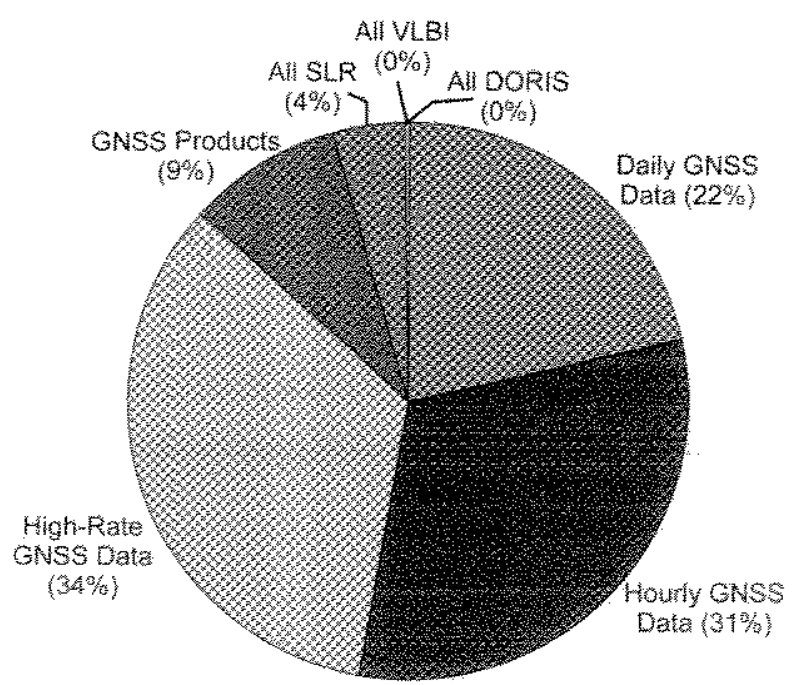

Fig. 6. The number of fles downloaded from the CDDIS archive in 2008 calegorized by data/product type. Due to the number of GNSS-related files, a further breakdown by data format and processing level is shown. 


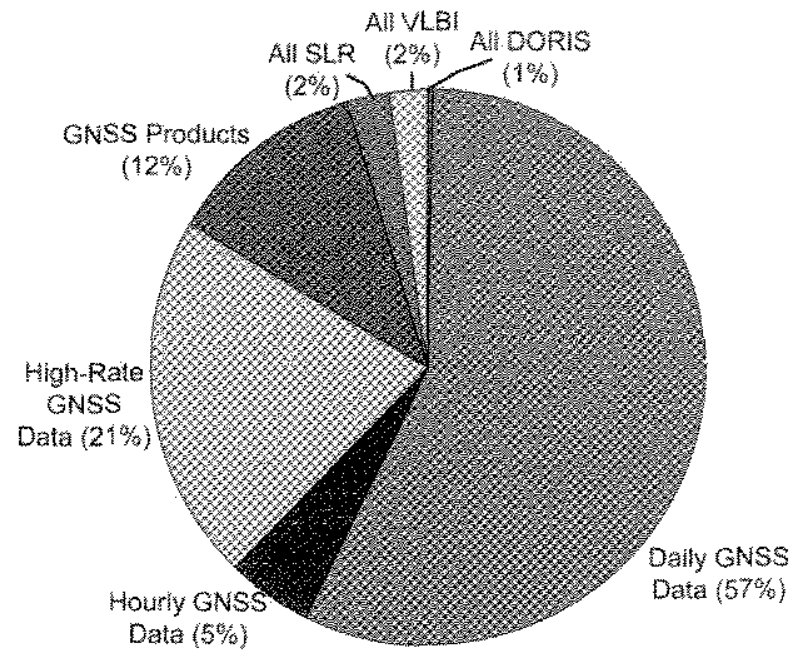

Fig. 7. The breakdown of CDDIS archive downloads by volume for 2008 , using the same method described in fig. 6.

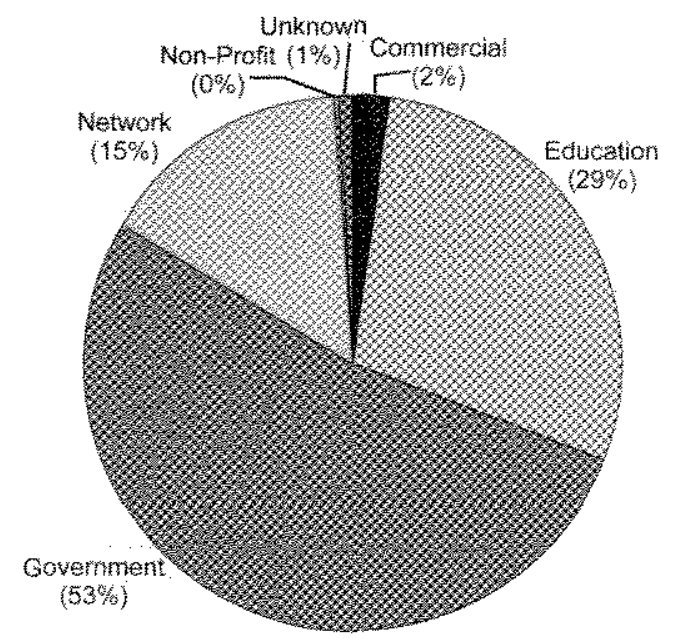

Fig. 8. Profile of users retrieving fles (based on volume) from the CDDIS archive in 2008 .

GNSS, which constitutes the majority $(95 \%)$ of those files distributed by the CDDIS. Fig. 7 presents the information by download volume. Taken together, Figs. 6 and 7 shows that general usage by technique is consistent but the format, span of data within the actual files, and size of the granules accounts for the differences, specifically in the GNSS areas. In particular the majority of DORIS-related files retrieved from the CDDIS in $2008(61 \%)$ consisted of derived products (orbit, time series of station positions, and ionospheremrelated files). Regarding DORIS data, most users continue to download multinday DORIS-formatted files (21\% of all DORIS-related files downloaded in 2008).

The CDDIS user community falls into three categories: science team (includes analysis centers supporting the IAG services), production users (includes other data centers populating their archives with selected fles from the CDDIS archive), and novice users (occasional users who access the system for specific files on an irregular basis). Science team users account for over half of all downloads from the archive with production and occasional users responsible for approximately $20 \%$ and $30 \%$ of file transfers respectively. In 2008, over 10.5 million files (or 1.2 Tbytes) were downloaded through ftp from the CDDIS archive each month. Fig. 8 categorizes the profile of users downloading these files from the CDDIS server. Government users, both U.S and international, represent the major portion of the CDDIS user community, with users from education institutions a close second. Specifically, over 100 distinct hosts retrieved DORIS data, products, or documentation files from the CDDIS in 2008 .

\section{Future plans}

The CDDIS data center is dedicated to supporting the international space geodesy community. Because of its specialized nature, the system is well suited to enhancement where internal processes can be easily modified to include new data sets and support additional user requirements.

\subsection{Data archive updates}

The IAG services will continue to develop new data sets and products. As a key data center supporting these services, the CDDIS will augment it's ingest and archive prom cedures to accommodate these files, ensuring the ability for users to access the new data records. The CDDIS will also support new NASA missions, such as ICESat-M, DESDynI, particularly in providing an archive for SLR and GPS tracking data.

Many of the space geodesy observation techniques are moving into the realm of near real-time data generation; the CDDIS plans to implement software to capture and record these real-time data streams, particularly in the GNSS data arena. Users can tap into these streams in order to create products on a near real-time basis that are also archived in the CDDIS and forwarded to other multidisciplinary science areas (e.g., for weather prediction, ionospheric weather, timing, etc.).

\subsection{User interface enhancements}

One area of improvement for the CDDIS is in discovery of the system's contents for both new users and for the existing user base. The average user of the CDDIS today accesses the contents of the archive through anonymous ftp by means of automated scripts. Analysts can use this method for data transfer because they are familiar with the structure of the CDDIS and thus know what files they require, their avallability schedule, and where to find them within the online structure. However, new users of the CDDIS, both those familiar with space geodesy techniques as well as new research communities, would prefer a brows- 
ing interface to the archive contents. Therefore, the CDDIS will undertake the design of a web interface based search tool that queries the CDDIS metadata. This process will require modification of the database schemas to reflect changes to the metadata. Use of internationally-recognized metadata standards, in cooperation with GGOS and EOSDIS, will be investigated. Users will have the ability to specify search criteria based on temporal, spatial, target, site designation, and/or observation parameter in order to identify data and products of interest for download. Results of these queries will inciude a listing of sites (or other metadata) or data holdings satisfying the user input specifications. Such a user interface will also aid CDDIS staff in managing the contents of the archive.

\subsection{Computer upgrades}

During early 2010, the CDDIS staff will complete the migration of operations to a distributed server environment. Distinct servers (with online backup components) have been procured to handle incoming, outgoing (i.e., ftp), and archive operations. Servers will handle load balancing on incoming queries for files. Additional RAID storage has been installed bringing the total available storage for CDDIS archive to 20 Tbytes. This increased capacity will satisfy near-term archive requirements (the CDDIS online archive grows by over one Tbyte each year).

\section{Concluding remarks}

The CDDIS is a mature data archive and information service, used by the international space geodesy community, particularly the International Association for Geodesy, for over 25 years. The system has provided continuous, long-term, public access to the data and products required for a variety of study areas, including the terrestrial reference frame. NASA has been (for over 35 years) and continues to be, one of the primary developers and supporters of the techniques utilized in space geodesy and the resulting data and analysis are facilitated through the CDDIS. The data center is dedicated to the support of these data records for the international space geodesy community, providing reliable, straightforward, and rapid access to a variety of data, products, and information about them. The focused nature of the CDDIS allows for easy modification and augmentation to efficiently accommodate new and varied data sets and user requirements. All data records, products, and information are publicly avallable online through web and anonymous ftp access.

\section{Acknowledgments}

The author would like to acknowledge the support of the organizations contributing to the IAG services, which wlimately provide content to the CDDIS for the international science community. Thanks also to the staff over the last 25mplus years, particularly Dr. Maurice Dube, who have worked to make the CDDIS a successful contributor to global science investigations.

\section{References}

Altamimi, $Z$., Collilieux, X., Legrand, J., et al. ITRF2005: A new release of the International Terrestrial Reference frame based on time series of station positions and Earth Orientation Parameters. J. Geophys. Res, 112, B09401, doi:10.1029/2007JB004949, 2007.

Altamimi, $z$, Coutot, D., Collilieux, $X$. Status of ITRF development and SLR contribution. In: Schilliak, S (Ed.), proceedings of the 16 th International Workshop on Laser Ranging, pp. 35 42, 2009.

Auriol, A., Tourain, C. DORIS system, the new age. Adv. Space Res., submitted for publication.

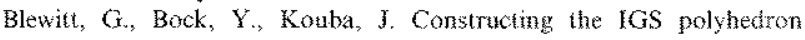
by distributed processing. In: Zumberge, W. Ed.), Proceedings of the IGS Workshop, IGS Centrat Bureat, Pasadena, CA, USA, $21-36,1995$.

Bosworth, J.M., Coates, R.3, Fischetti, T.L. The development of NASA's crustal dynamics project. In: Contributions of Space Geodesy to Geodymamies: Technology. AGU Geodymamics Series $25,1-20,1993$.

Committee on Eartl Science and Applications from Space: A Community Assessment and Strategy for the Future; National Research Council. "Earth Science and Applications from Space: National Imperatives for the Next Decade and Beyond", ISBN: 0-309\%+66900-6, 2007.

Degnan, J.J. 30 Years of SLR. In: Luck, J. (Ed.), Proceedings of the 9 th International Workshop on Laser Ranging Instrumentation, AustaJan Government Publishing Service, Canberta, pp. 8-20, 1994.

Dow, J.M., Neilan, R.E., Rizos, C. The International GNSS Service in a changing landscape of Global Navigation Satellite Systems. J. Geod. 83 (3-4), 191-198, doi:10.1007/s00190)008-0300-3, 2008.

Ferland, R. Consistency of the $I G S$ contribution to ITRF2008. Geophys. Res. Abs. 11, EGU2009-5037-1, 2009.

Ferland, R., Piraszewsk, M. The IGS-combined station coordinates, earth rotation parameters and apparent geocenter, J. Geod. $83(34), 385$ 392, do: $10.1007 / \mathrm{s} 00190-008-0295-9,2009$.

Griffiths, J., Ray, J. On the precision and accuracy of IGS orbits. J. Geod. $83(3-4), 277-287$, doi: $10,1007 / \mathrm{s} 00990-008-0237-6,2009$.

Gross, R. Laser ranging contributions to earth rotation studies. In: Schilliak, S. (Ed.), Proceedings of the 16th International Workshop on Laser Ranging, pp. 10-15, 2009.

Gurmer, W. RINEX: the receiver-independent exchange format. GPS World $5(7), 48-52,1994$.

Gurtner, W., Mader, G., MacArthur, D. A common exchange format for GPS data. GPS Bulletin 2 (3), 1-11, 1989.

Hatanaka, Y. A RINEX compression format and tools. In: Proceedings of ION GPS-96, pp. 177-183, September 1720, 1996.

Hilla, S. Extending the standard product 3 (SP3) orbit format. In: Proceedings of the International GPS Service Network, Data, and Analysis Center Workshop, Ottawa, Canada, April 8 11, 2002.

Nol, C., Soudarin, L. On-line resources suppoting the data, products, and information infrastructure for the international DORIS Service. 1. Geod. $80(8-11), 419-427$, doi: $10.1007 / \mathrm{s} 00190 \cdots 0060051-y, 2006$.

Noll, C., Bock. Y., Habrich, H., et al. Development of data infrastructure to support scienific analysis for the Interuational GNSS Service. I. Geod. 83 (3-4), 309326 , doi $10.100 \% / \mathrm{s} 00190-008-02456,2009$

Pavliu, E. Kurmicz-Cieslak, M. Geocenter motion: causes and modeling approaches. In: Schilliak, S. (Ed.), Proceedings of the 16 th Interna tional Workshop on Laser Ranging, pp. 16-26, 2009.

Pearlman, M.R., Degnan, J.J., Bosworth, J.M. The international hast ranging service. Adv. Space. Res. 30 (2), 135 143, do: 10.1016/S0273. $1177(02) 00277-6,2002$.

Plag, H.P., Pearman, M. (Eds,). The Global Geodetic Observing System: Meeting the Requirements of a Global Society on a Changing Planet in 2020. Springer, Berlin Heidelberg, doi:10.1007/978-3-642-62687+4. 2009 . 
Ray, J., Griffiths, J. Preliminary analysis of IGS reprocessed orbit and polar motion estimates. Geophys. Res. Abs. 11 (EGU2009-503\%- ]) 2009.

Ricklefs. R. Consolidated laser prediction and data formats: supporting new technology, in: Luck, J., Moore, C., Wilson, P. (Eds.), Proceedings of the 15th International Workshop on Laser Ranging. Canberra, EOS Space Systems Pty Limited, Canberra, Australia, pp. $535-538,2008$.

Schlüter, W., Behrend, D. The intemational VLBI service for geodesy and astrometry (IVS): current capabilities and future prospects. J. Geod. 81 (6-8), 379-387, do: 10.1007/s00190-006-0131-z, 2007.

Tavernier, G., Granier, J.P., Jayles, C., et al. The current evolution of the DORIS system. Adv. Space Res. 31 (8), 1947-1952, doi:10.1016/ S0273-1177(03)00155-8, 2003 .
Tavernier, G., Fagard, H., Feissel-Vernier, M., et at. The international DORIS service: genesis and early achievements. J. Geod, 80 (8-11), 403-417, doi:10.1007/500190-006-0082-4, 2006.

Williams, J.G., Dickey, J.O. Lunar Geophysics, Geodesy, and Dynamics. In: Noomen, R., Klosko, S., Noll, C., Pearlman, M. (Eds.), Proceedings from the Science Session and Full Proceedings CD-ROM, NASA CP-2003-212248, 2003.

Willis, P., Boucher, C., Fagard, fl., et al. Geodetic applications of the DORIS system at the French 'Institut Geographique National'. CR Geosci. 337 (7), 653-662, doi:10.1016/j.crte.2005.03.002, 2005.

Willis, P., Fagard, H., Ferrage, P., et al. The international DORIS service (DDS): toward maturity. Adv. Space Res. 45(12), 1408 1420, doi: $10.1016 / 1.45 .2009 .11 .018,2010$. 